\title{
Tibial plateau fractures: compared outcomes between ARIF and ORIF
}

\author{
C. Dall'Oca $\cdot$ T. Maluta $\cdot$ F. Lavini $\cdot$ \\ M. Bondi · G. M. Micheloni • P. Bartolozzi
}

Received: 23 July 2011/ Accepted: 8 October 2012/Published online: 20 October 2012

(C) The Author(s) 2012. This article is published with open access at Springerlink.com

\begin{abstract}
The purpose of this study is to compare arthroscopic assisted reduction internal fixation (ARIF) treatment with open reduction internal fixation (ORIF) treatment in patients with tibial plateau fractures. We studied 100 patients with tibial plateau fractures (54 men and 46 women) examined by X-rays and CT scans, divided into 2 groups. Group A with associated meniscus tear was treated by ARIF technique, while in group B ORIF technique was used. The follow-up period ranged from 12 to 116 months. The patients were evaluated both clinically and radiologically according to the Rasmussen and HSS (The Hospital for Special Surgery knee-rating) scores. In group A, the average Rasmussen clinical score is $27.62 \pm 2.60$ (range, 19-30), while in group $\mathrm{B}$ is $26.81 \pm 2.65$ (range, 21-30). HSS score in group A was $76.36 \pm 14.19$ (range, 38-91) as the average clinical result, while in group B was $73.12 \pm 14.55$ (range, 45-91). According to Rasmussen radiological results, the average score for group A was $16.56 \pm 2.66$ (range, $8-18$ ), while in group B was $15.88 \pm 2.71$ (range, 10-18). Sixty-nine of 100 patients in our study had associated intra-articular lesions. We had 5 early complications and 36 late complications. The study suggests that there are no differences between ARIF and ORIF treatment in Schatzker type I fractures. ARIF technique may increase the clinical outcome in Schatzker type II-III-IV fractures. In Schatzker type V and VI fractures, ARIF and ORIF techniques have both poor medium- and long-term results but ARIF
\end{abstract}

C. Dall'Oca $(\bowtie) \cdot$ T. Maluta · F. Lavini · M. Bondi ·

G. M. Micheloni · P. Bartolozzi

Department of Surgery, Orthopaedic and Traumatology Clinic,

G.B. Rossi Hospital, University of Verona,

Piazzale Scuro 10, 37134 Verona, Italy

e-mail: carlo.dalloca@univr.it treatment, when indicated, is the best choice for the lower rate of infections.

Keywords Tibial plateau fractures - ARIF .

Arthroscopically assisted reduction · Post-traumatic arthrosis · External fixation

\section{Introduction}

Tibial plateau fractures are complex injuries of the articular and the metaphyseal segments. Surgery is challenging due to the fracture patterns and the associated complications. The displacement of the bony fragments and pattern of involvement of subchondral bone and cartilage characterize the severity of the lesion and treatment strategy. The associated soft-tissue damage, knee instability, meniscal lesions and possibility of compartment syndrome also influence treatment methods [1-11].

Open reduction and internal fixation (ORIF) with plates and screws is an established method of treatment for complex fractures (Schatzker types V-VI). ORIF strategy has undergone refinement with the advent of external fixators into the treatment plan and introduction of low profile plates and anatomic periarticular implants [12-14]. External circular fixation is used for complex fractures with softtissue damage because of the advantage of being minimally invasive and a potential to reduce deep infection [8, 15-23]. External fixators are also used as a temporary stabilization frames across the knee joint for pain relief, provisional reduction and soft-tissue control; CT scans are obtained for pre-operative planning [17, 24, 25]. Recently, we have observed a progressive modification of the treatment from ORIF to arthroscopic assisted reduction and internal fixation (ARIF) [14, 24, 26-28]. Some authors recommend 
ARIF for Schatzker type I, II, III, IV whilst a few have done the same for type V and VI fractures [6, 9, 14, 23, 2831].

The aim of this retrospective study was to compare the results obtained by ARIF versus ORIF treatment.

\section{Materials and methods}

The study relates to patients with tibial plateau fractures treated between March 2000 and December 2009. There were 100 patients, 54 men and 46 women with a mean age of 51 years (range 13-77), who underwent operative surgery. There were 14 cases of type I fracture, 12 type II, 44 type III, 8 type IV, 12 type V and 10 type VI, according to the Schatzker classification [32]. In order to decide treatment, all patients were assessed using X-rays and CT scans $[25,33]$. If an associated meniscal tear was present, the patient was treated with the ARIF technique. Otherwise the ORIF technique was used, avoiding arthrotomy where possible. For Schatzker V and VI fractures, the ARIF technique was used only in selected cases where a low degree of comminution was present.

There were two groups: group A (ARIF; composed of 50 patients of whom 23 were males) and group B (ORIF; composed of 50 patients of whom 31 were males). The exclusion criteria were: open fractures; pathologic fractures; significant pre-existing degenerative joint disease; severe systemic illness (active cancer, chemotherapy, renal failure or other comorbidities that contraindicate surgery) or a neurological condition that would interfere with rehabilitation. The follow-up period ranged from 12 to 116 months, with a mean of 73, 27 months. No patients were lost to follow-up.

Sixty-four patients were injured in traffic accidents, 24 in sport injuries (ski, motorbike, bicycle and rugby) and 12 by a simple fall. Eighteen of them had associated fractures ( 2 clavicle fractures, 12 distal radial fractures and 4 proximal humerus fractures) all of which were treated with conservative methods. The patients were evaluated as follows: soft-tissue condition using the Tscherne classification, sensorimotor function of the limb by a clinical neurological examination and vascular status by Doppler.

The mean time between day of admission and surgery was 4 days (range 2-10 days) and the timing of surgery was influenced by the patient's general and the soft-tissue envelope conditions, in particular significant oedema and skin blisters [34].

Type I fractures were treated using cannulated screws, type II by plates and screws, type III by cannulated screws or plates and screws. Type IV, V and VI were treated by plates and screws with cannulated screws added if needed;

Table 1 Patient's data, treatment and associated lesions

\begin{tabular}{|c|c|c|c|c|c|c|c|c|c|c|c|c|}
\hline \multirow{2}{*}{$\begin{array}{l}\text { Classification } \\
\text { Treatment }\end{array}$} & \multicolumn{2}{|c|}{$\begin{array}{l}\text { Schatzker I } \\
\text { (n.14) }\end{array}$} & \multicolumn{2}{|c|}{$\begin{array}{l}\text { Schatzker II } \\
\text { (n.12) }\end{array}$} & \multicolumn{2}{|c|}{$\begin{array}{l}\text { Schatzker III } \\
\text { (n.44) }\end{array}$} & \multicolumn{2}{|c|}{$\begin{array}{l}\text { Schatzker IV } \\
\text { (n.8) }\end{array}$} & \multicolumn{2}{|c|}{$\begin{array}{l}\text { Schatzker V } \\
\text { (n.12) }\end{array}$} & \multicolumn{2}{|c|}{$\begin{array}{l}\text { Schatzker VI } \\
\text { (n.10) }\end{array}$} \\
\hline & ARIF & ORIF & ARIF & ORIF & ARIF & ORIF & ARIF & ORIF & ARIF & ORIF & ARIF & ORIF \\
\hline Patient & 4 & 10 & 7 & 5 & 26 & 18 & 5 & 3 & 4 & 8 & 4 & 6 \\
\hline Age & 33.29 & 44.14 & 54.33 & 53.67 & 51.64 & 48.5 & 53.75 & 64.25 & 51.33 & 45 & 38.8 & 51.4 \\
\hline \multicolumn{13}{|l|}{ Gender } \\
\hline M & 2 & 6 & 4 & 3 & 10 & 13 & 3 & 2 & 3 & 3 & 1 & 4 \\
\hline $\mathrm{F}$ & 2 & 4 & 3 & 2 & 16 & 5 & 2 & 1 & 1 & 5 & 3 & 2 \\
\hline \multicolumn{13}{|l|}{ Side } \\
\hline $\mathrm{R}$ & 1 & 7 & 2 & 1 & 14 & 14 & 3 & 1 & & 6 & 4 & 3 \\
\hline $\mathrm{L}$ & 3 & 3 & 5 & 4 & 12 & 4 & 2 & 2 & 4 & 2 & & 3 \\
\hline \multicolumn{13}{|l|}{ Treatment } \\
\hline Cannulated screws & 4 & 10 & & & 14 & 7 & 1 & 2 & 3 & 5 & 3 & 4 \\
\hline Plate + screws & & & 7 & 5 & 12 & 11 & 4 & 4 & 3 & 7 & 2 & 4 \\
\hline Circular external fixation & & & & & & & & & 1 & 1 & 2 & 2 \\
\hline Transarticular external fixation & & & & & & & & & 2 & 3 & 2 & 3 \\
\hline \multicolumn{13}{|l|}{ Associated lesions } \\
\hline None & & 10 & & 2 & 11 & 8 & & & & & & \\
\hline Meniscus & 4 & & 5 & 2 & 13 & 10 & 3 & 2 & 4 & 7 & 4 & 3 \\
\hline ACL & & & 2 & & 2 & & 2 & 1 & 1 & 2 & 2 & 2 \\
\hline PCL & & & & & & & 1 & 1 & & 1 & & \\
\hline MCL & & & & 1 & & & & & 2 & & 2 & 2 \\
\hline LCL & & & & & & & & 1 & & & & \\
\hline
\end{tabular}


in three Schatzker V and three Schatzker VI fractures, double plates were used through two incisions; for the remainder of type V and VI fractures, we used a circular external fixator as definitive treatment as the metaphysis was highly comminuted or the soft-tissue conditions were of Tscherne grade 3 [35]. With high energy fractures, it was necessary to wait for better local conditions in order to perform internal synthesis and for this reason temporary bridging external fixators were used.

In this series, 6 cases ( 2 Schatzker V and 4 Schatzker VI fracture) were treated with circular fixators and 10 (5 Schatzker V and 5 Schatzker VI fracture) with temporary bridging external fixators to be followed by ORIF.
Joint distension during ARIF treatment was accomplished by intra-articular fluid infusion by gravity with a third portal used for venting to prevent extravasation increases in joint pressure.

Bone grafts taken from the iliac crest were used in 3 cases (3\%).

Knee motion was allowed 10 days after surgery in both groups. Partial weight bearing was permitted at an average of 6.3 weeks post-operatively and full weight bearing at 9.0 weeks in both groups (Table 1).

The patients were evaluated clinically and radiologically using the Rasmussen and HSS (The Hospital for Special Surgery knee-rating score) systems. This provided a record

Table 2 Rasmussen, HSS scores and complications

\begin{tabular}{|c|c|c|c|c|c|c|c|c|c|c|c|c|}
\hline \multirow{2}{*}{$\begin{array}{l}\text { Classification } \\
\text { Treatment }\end{array}$} & \multicolumn{2}{|c|}{$\begin{array}{l}\text { Schatzker I } \\
\text { (n.14) }\end{array}$} & \multicolumn{2}{|c|}{$\begin{array}{l}\text { Schatzker II } \\
\text { (n.12) }\end{array}$} & \multicolumn{2}{|c|}{$\begin{array}{l}\text { Schatzker III } \\
(\mathrm{n} .44)\end{array}$} & \multicolumn{2}{|c|}{$\begin{array}{l}\text { Schatzker IV } \\
\text { (n.8) }\end{array}$} & \multicolumn{2}{|c|}{$\begin{array}{l}\text { Schatzker V } \\
\text { (n.12) }\end{array}$} & \multicolumn{2}{|c|}{$\begin{array}{l}\text { Schatzker VI } \\
\text { (n.10) }\end{array}$} \\
\hline & ARIF & ORIF & ARIF & ORIF & ARIF & ORIF & ARIF & ORIF & ARIF & ORIF & ARIF & ORIF \\
\hline Patient & 4 & 10 & 7 & 5 & 26 & 18 & 5 & 3 & 4 & 8 & 4 & 6 \\
\hline \multicolumn{13}{|c|}{ Rasmussen clinical assessment } \\
\hline Pain & 5.75 & 5.7 & 5.42 & 5.2 & 5.69 & 5.44 & 5 & 4.33 & 4.75 & 4.5 & 4.5 & 4.67 \\
\hline Walking capacity & 6 & 6 & 5.29 & 5.2 & 5.69 & 5.67 & 5.6 & 4.67 & 4.5 & 4.75 & 4.5 & 4.67 \\
\hline Extension & 6 & 6 & 5.71 & 5.6 & 5.54 & 5.67 & 5.6 & 5.33 & 4.5 & 4.75 & 4.5 & 4.33 \\
\hline ROM & 6 & 5.9 & 5.29 & 5.2 & 5.69 & 5.22 & 4.8 & 4.67 & 5 & 4.5 & 4.75 & 4.5 \\
\hline Stability & 6 & 6 & 6 & 6 & 6 & 6 & 5.4 & 5.67 & 5.75 & 5.38 & 5.25 & 5.17 \\
\hline TOT & 29.75 & 29.6 & 27.71 & 27.2 & 28.62 & 28 & 26.4 & 24.67 & 24.5 & 23.84 & 23.5 & 23.3 \\
\hline \multicolumn{13}{|c|}{ Rasmussen radiological assessment } \\
\hline Depression & 6 & 6 & 6 & 5.2 & 5.77 & 5.67 & 5.2 & 4 & 4 & 4.75 & 4 & 4.33 \\
\hline Condylar widening & 6 & 6 & 5.43 & 5.6 & 5.77 & 5.89 & 6 & 5.33 & 5 & 5 & 4 & 4 \\
\hline Angulation (varus/valgus) & 6 & 6 & 5.71 & 5.6 & 5.85 & 5.78 & 5.2 & 5.33 & 5 & 4 & 3.5 & 2.67 \\
\hline TOT & 18 & 18 & 17.14 & 16.4 & 17.38 & 17.33 & 16.4 & 14.67 & 14 & 13.75 & 11.5 & 11 \\
\hline \multicolumn{13}{|l|}{ HSS score } \\
\hline Pain & 30 & 30 & 21.43 & 18 & 22.31 & 20.28 & 13 & 8.33 & 8.75 & 8.75 & 7.5 & 8.33 \\
\hline Function & 12 & 11.8 & 11.14 & 11.6 & 11.54 & 11.67 & 11.2 & 10 & 10 & 10.5 & 9 & 8.67 \\
\hline $\mathrm{ROM}$ & 17.5 & 17.4 & 16.57 & 16.8 & 17.23 & 16.44 & 15.2 & 15.33 & 15.25 & 13.75 & 14.5 & 14.5 \\
\hline Muscle strength & 10 & 9.8 & 9.14 & 9.2 & 9.69 & 9.56 & 9.2 & 7.33 & 8.5 & 8.25 & 8 & 9 \\
\hline Flexion deformity & 10 & 10 & 8.57 & 9.2 & 9.42 & 9.17 & 9 & 8.67 & 7.5 & 6.63 & 7.5 & 7.67 \\
\hline Instability & 10 & 10 & 10 & 10 & 10 & 10 & 9 & 8.67 & 7.5 & 8.13 & 8.75 & 6.67 \\
\hline Subtraction & 1 & 1 & 1 & 1 & 1.04 & 1 & 1 & 1 & 1.25 & 1.25 & 1.25 & 1 \\
\hline TOT & 90.5 & 90 & 77.86 & 75.8 & 81.23 & 78.11 & 67.6 & 59.33 & 58.75 & 57.25 & 56.5 & 55.83 \\
\hline \multicolumn{13}{|l|}{ Complications } \\
\hline \multicolumn{13}{|l|}{ Early complications } \\
\hline SPE stupor & & & & 1 & & & & & & & & \\
\hline TVP & & & & & & & & & & & 1 & 1 \\
\hline Superficial infection & & & & & & & & & & 2 & & \\
\hline \multicolumn{13}{|l|}{ Late complications } \\
\hline Deep infection & & & & & & & & & & 1 & & 1 \\
\hline Algodystrophy & & & & & & & & & & 2 & & 2 \\
\hline Intolerance fixation & & & 2 & 3 & 4 & 6 & 2 & 2 & 1 & 5 & 2 & 3 \\
\hline
\end{tabular}


of functional and anatomic results after treatment [36, 37]. The follow-up protocol included analysis of subjective complaints and objective clinical findings. Radiographic evaluations were done pre-operatively, at 3,6 months and 1 year post-operatively. Standing X-rays of the knee were evaluated at each year interval from surgery in order to detect joint depression, articular degeneration and axial changes.

\section{Results}

In group $\mathrm{A}$, the average Rasmussen clinical score is $27.62 \pm 2.60$ (range 19-30). Scores related to each Schatzker type of fractures are reported in Table 2. The following scores were obtained: 29.75, 27.71, 28.62, 26.4, 24.5 and 23.5, respectively, for Schatzker I, II, III, IV, V and VI types of fracture. In group B, the average Rasmussen clinical score is $26.81 \pm 2.65$ (range 21-30).

Analysing the clinical scores for each type of fracture, 29.6, 27.2, 28, 24.67, 23.84 and 23.3 were obtained, respectively, for Schatzker I, II, III, IV, V and VI types.

Using the HSS score, group A had $76.36 \pm 14.19$ (range 38-91) on average.

The HSS scores for each type of fracture were 90.5, 77.86, 81.23, 67.6, 58.75 and 56.5, respectively, for Schatzker I, II, III, IV, V and VI types.

In group B, the average HSS score was $73.12 \pm 14.55$ (range 45-91).

The scores for each type of fracture were 90, 75.8, 78.11, 59.33, 57.25 and 55.83, respectively, for Schatzker I, II, III, IV, V and VI types.

According to Rasmussen radiological results, the average score for group $\mathrm{A}$ is $16.56 \pm 2.66$ (range 8-18). The scores for each type of fracture were 18, 17.14, 17.38, 16.4, 14 and 11.5, respectively, for Schatzker I, II, III, IV, V and VI types. In group B, the average score was $15.88 \pm 2.71$ (range 10-18). The scores for each type of fracture were $18,16.4,17.33,14.67,13,75$ and 11 , respectively, for Schatzker I, II, III, IV, V and VI types.

Associated injuries and procedures

Sixty-nine of 100 patients in our study had associated intraarticular lesions. Of the remaining 31 patients, without associated lesions, 20 of them belonged to group B while 11 patients belonged to group A. A lesion of the meniscus was found in 57 knees: a medial meniscus tear in 13 knees; a lateral meniscus tear in 34 knees and bilateral meniscal tears in 10 knees. Thirty-two menisci were sutured, 21 partially resected and 4 totally removed.

Ruptures or avulsions of ligaments were found in 25 knees, including 14 anterior cruciate ligament avulsions, 3 posterior cruciate ligament ruptures, 1 lateral collateral ligament avulsion at the fibular insertion, 7 medial collateral ligament partial ruptures and 3 combination of anterior cruciate ligament and medial collateral ligament partial ruptures. Eight anterior cruciate ligament lesions were treated arthroscopically, 6 lesions were treated with a

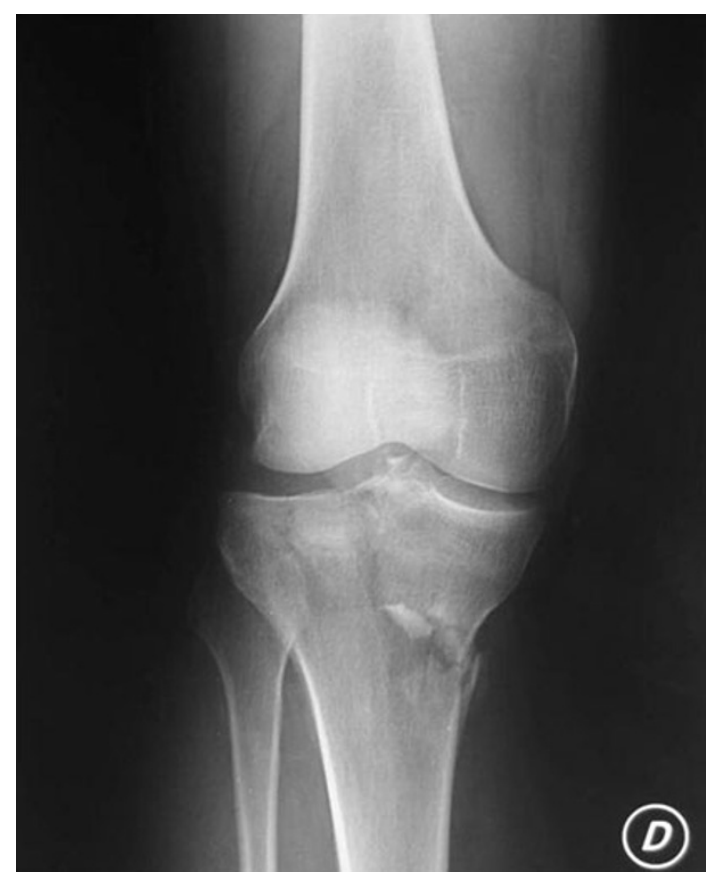

Fig. 1 Schatzker type IV fracture, pre-op X-rays (AP)

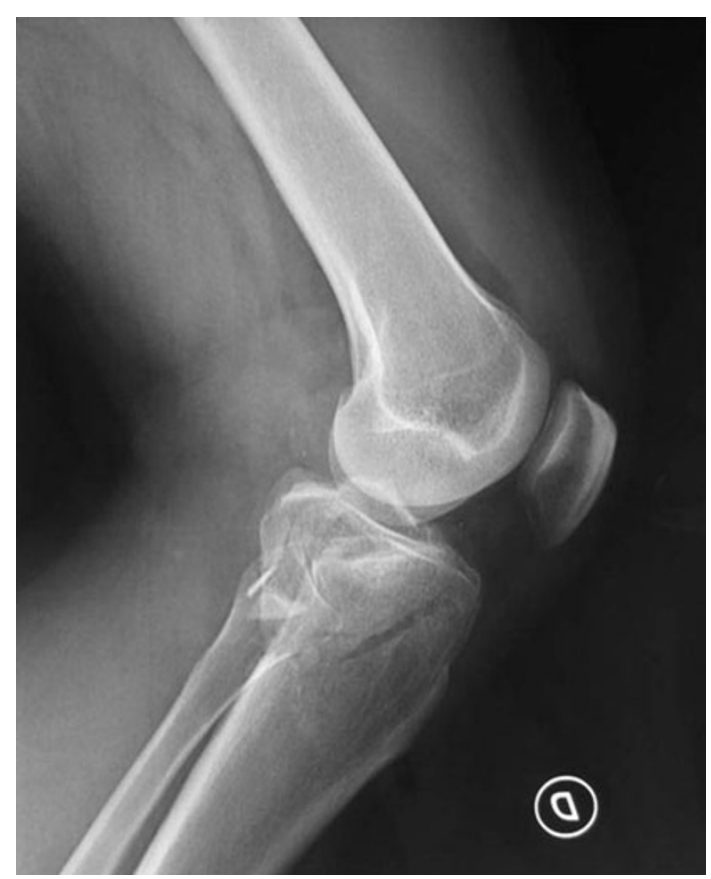

Fig. 2 Schatzker type IV fracture, pre-op X-rays (LL) 
A

B

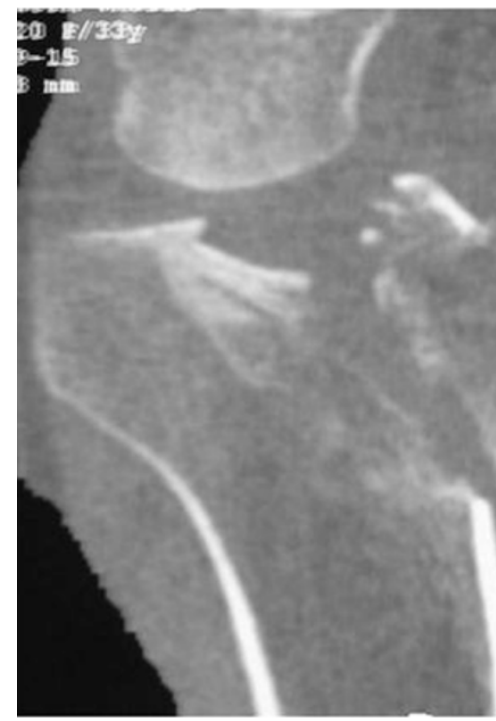

C
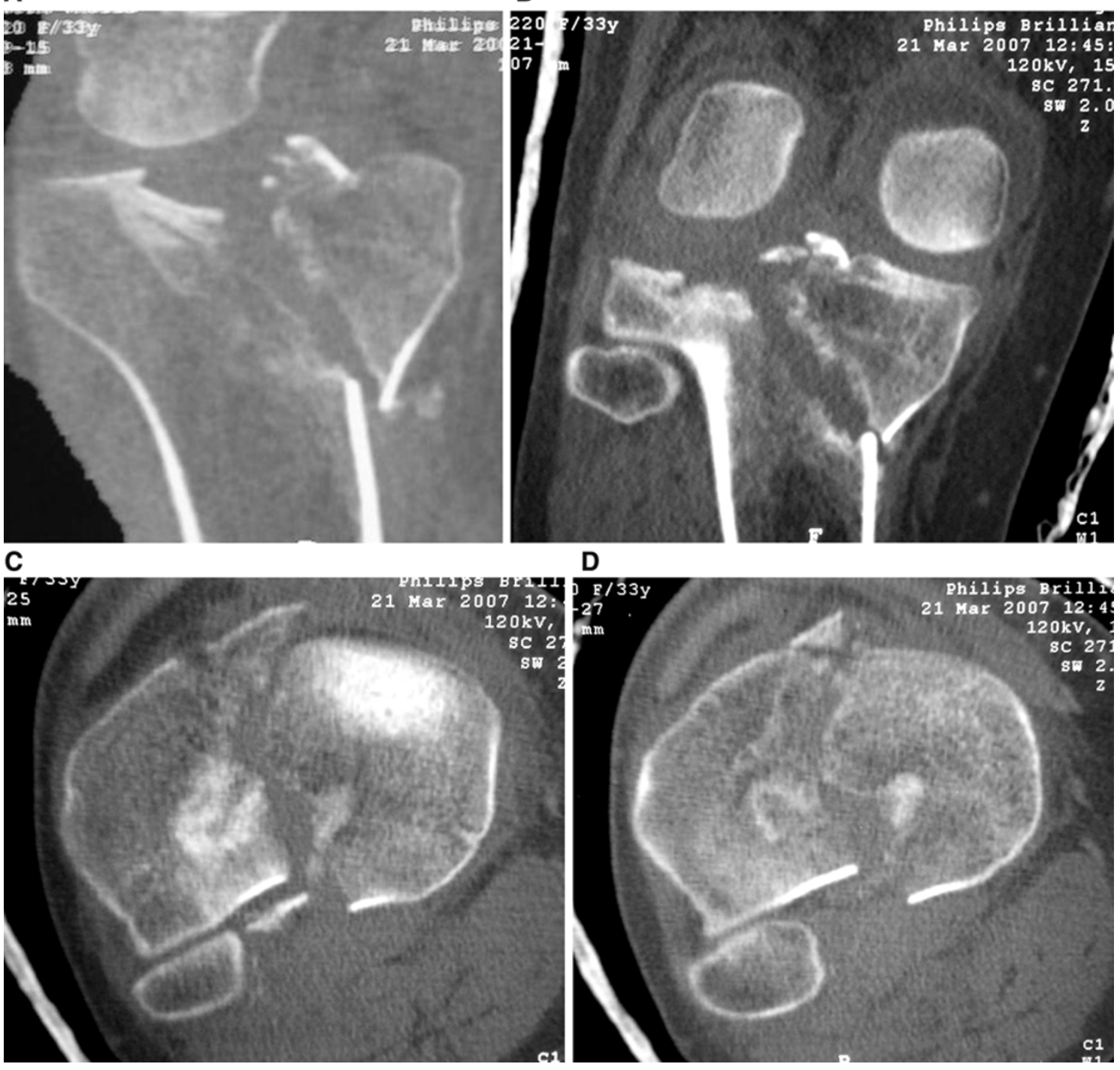

D

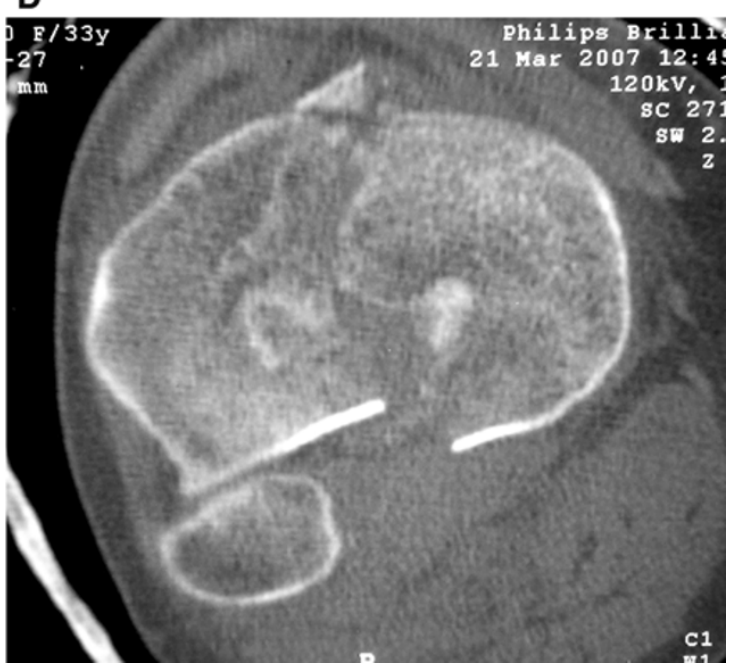

Fig. 3 a Schatzker type IV fracture, CT scan. b Schatzker type IV fracture, CT scan. c Schatzker type IV fracture, CT scan. d Schatzker type IV fracture, CT scan

secondary reconstruction of the ligament. The lateral collateral ligament avulsion was fixed.

\section{Complications}

There were no complications directly associated with arthroscopic procedures in group A. There were two cases of deep vein thrombosis: one in group A and one in group B. One patient who underwent ORIF treatment developed a common peroneal nerve neurapraxia which recovered fully in 4 months. There are no post-operative incidences of compartment syndrome in either group.

Two patients in group B had a superficial infection treated with antibiotic therapy after sample culture and identification of bacteria. Two deep infections occurred in ORIF group: one in a type $\mathrm{V}$ and one in a type VI fracture. The first (type V) was probably due to a proximal pin site infection from the temporary external fixator and was treated by removal of the device and substitution with an antibiotic-embedded cement spacer. The spacer was maintained for 8 months and, when there was no evidence of infection relapse through labelled-leucocyte scintigraphy and serological markers, a knee prosthesis was inserted. The second (Schatzker VI) healed in a cast with ongoing chronic infection despite fixation implant removal. Completion of treatment was not feasible in this case due to mental health issues and lack of compliance with the patient.

There were 10 cases of intolerance to the medial plates and 20 to the lateral plates: six patients in group B and four in 
A

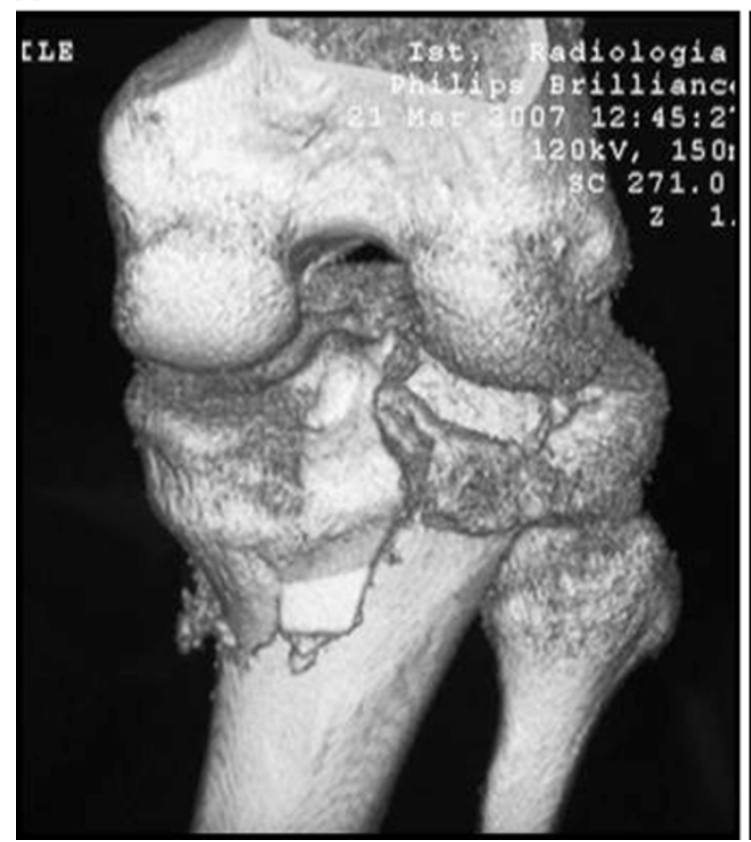

B

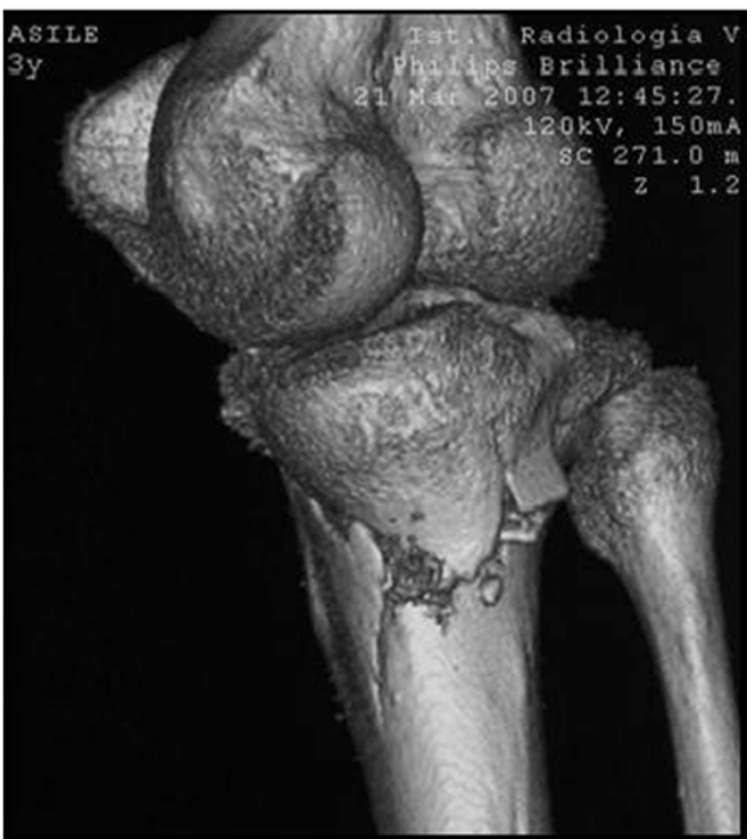

Fig. 4 a Schatzker type IV fracture, CT 3D reconstruction. b Schatzker type IV fracture, CT 3D reconstruction

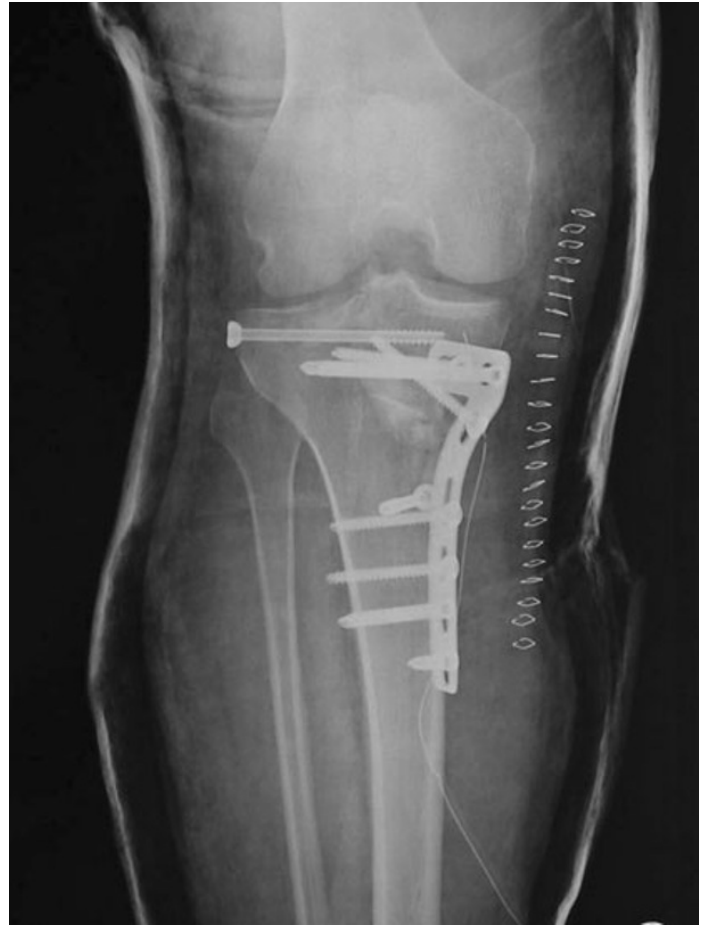

Fig. 5 Schatzker type IV fracture, post-op X-rays (AP)

group A needed the medial plates removed and 13 patients in group B and seven in group A needed the same for the lateral plates. No mechanical failures were observed. Four patients in group B developed algodystrophy which was treated with hyperbaric oxygen therapy and anti-osteoporotic drugs.

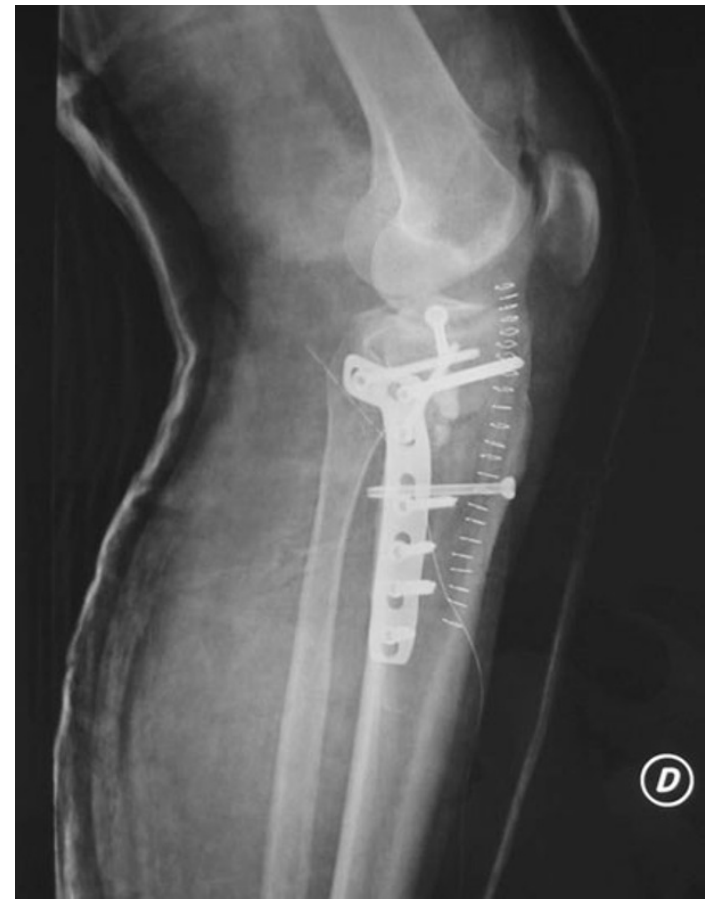

Fig. 6 Schatzker type IV fracture, post-op X-rays (LL)

One case in group A (41 years old) had residual valgus angulation and arthritis after 1 year which was treated with uni-compartmental knee prosthesis. Two cases in group B (67 and 69 years old) developed degenerative arthritis with a significant post-traumatic valgus alignment and were treated with a total knee prosthesis (Table 2). 


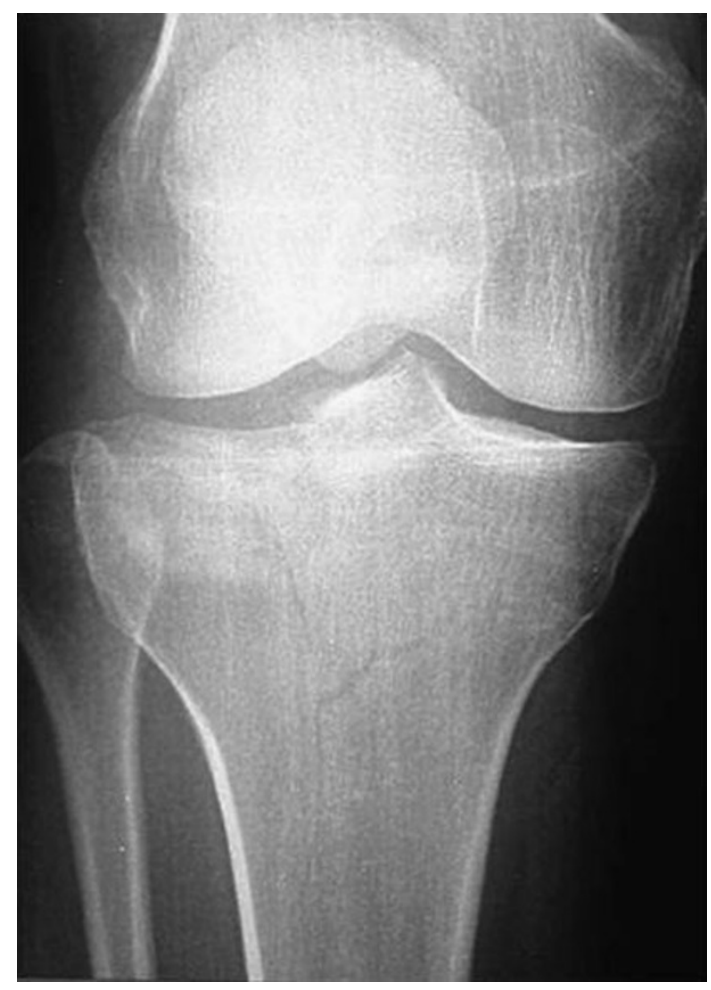

Fig. 7 Schatzker type V fracture, pre-op X-rays (AP)

\section{Discussion}

The standard of treatment for tibial plateau fractures is an anatomic reduction in the articular surface with stable fixation to allow early recovery of range of motion. It is also important to avoid ligamentous laxity in order to prevent late knee instability.

Several reports support arthroscopic management of tibial plateau fractures $[4-6,9,11-13,15-17,19,20,22$, 26, 28]. We observed that type I fractures had excellent results in both groups. There was no post-traumatic sequel from the approach. Schatzker II fractures, characterized by greater displacement and lateral cortex disruption, were associated often with a lateral meniscus lesion and an MCL or ACL lesion. Excellent results were obtained in both groups but with the ARIF technique, we were able to check and treat the associated injuries. We observed that patients treated by ARIF technique showed better values of ROM and sustained less pain than patients of group B, particularly within 12 months after surgery (Table 2). This was clinically important but was not statistically different due to the small numbers in each group. There was one early complication: a common peroneal nerve neurapraxia which recovered spontaneously after 4 months. Five cases $(41.7 \%)$ of late complications from the intolerance of the lateral implant were treated by plate removal.

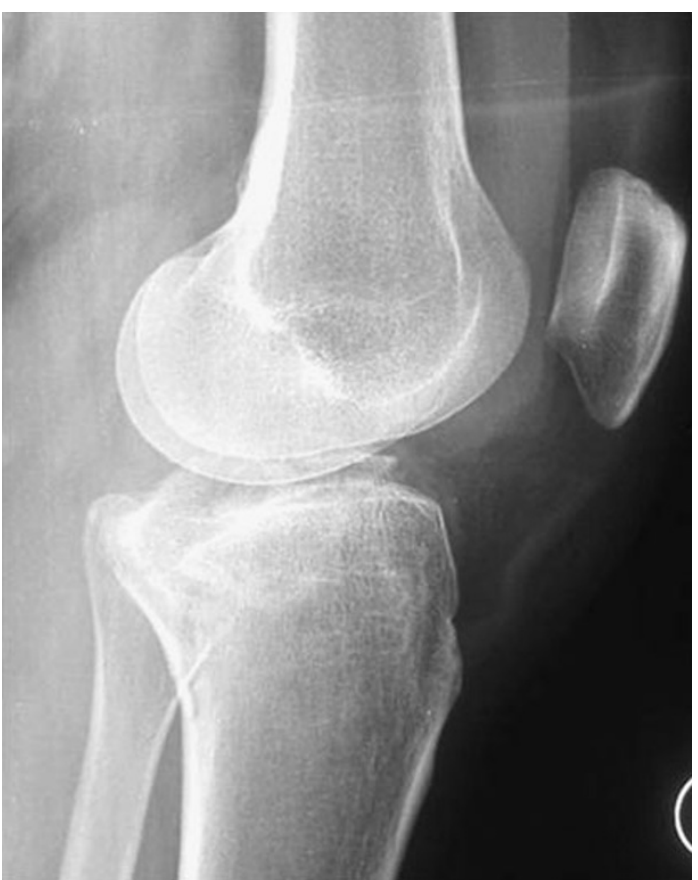

Fig. 8 Schatzker type V fracture, pre-op X-rays (LL)

In type III fractures treated by ARIF and ORIF, excellent results were obtained in both groups. There was a high incidence of lateral meniscus lesions, suggesting ARIF treatment being better suited in order to identify and treat these problems as well as aid in restoration of articular congruity. There were late complications: ten cases $(22.7 \%)$ of the lateral plates had to be removed. We noted that Schatzker III type fractures treated either by ARIF and ORIF techniques had better results than Schatzker II type fractures.

Schatzker IV type fractures (Figs. 1, 2, 3a-d, 4a, b, 5, 6) treated by ARIF technique demonstrated better results than those treated by ORIF. This may have been achieved because the procedure of avoided arthrotomy, with a temporary reduction by manipulation and confirmation of reduction by arthroscopy allowing surgical objectives to be accomplished with minimal damage to the capsule of the joint. On restoration of articular congruity, reduction was maintained with cannulated screws or, when needed, a medial plate applied without arthrotomy [38, 39]. This type of fracture is characterized by many associated injures ( 5 medial meniscus tears, 3 ACL, 2 PCL and 1 LCL ruptures). In ARIF group, the meniscal lesions were treated after the reduction and fixation of the fracture, whereas the ACL was reconstructed after fracture union. The LCL lesion occurred in ORIF group which was treated at the same time. There were late complications observed: plate intolerance due to interference at the insertion of the hamstrings tendons were treated by removal. 


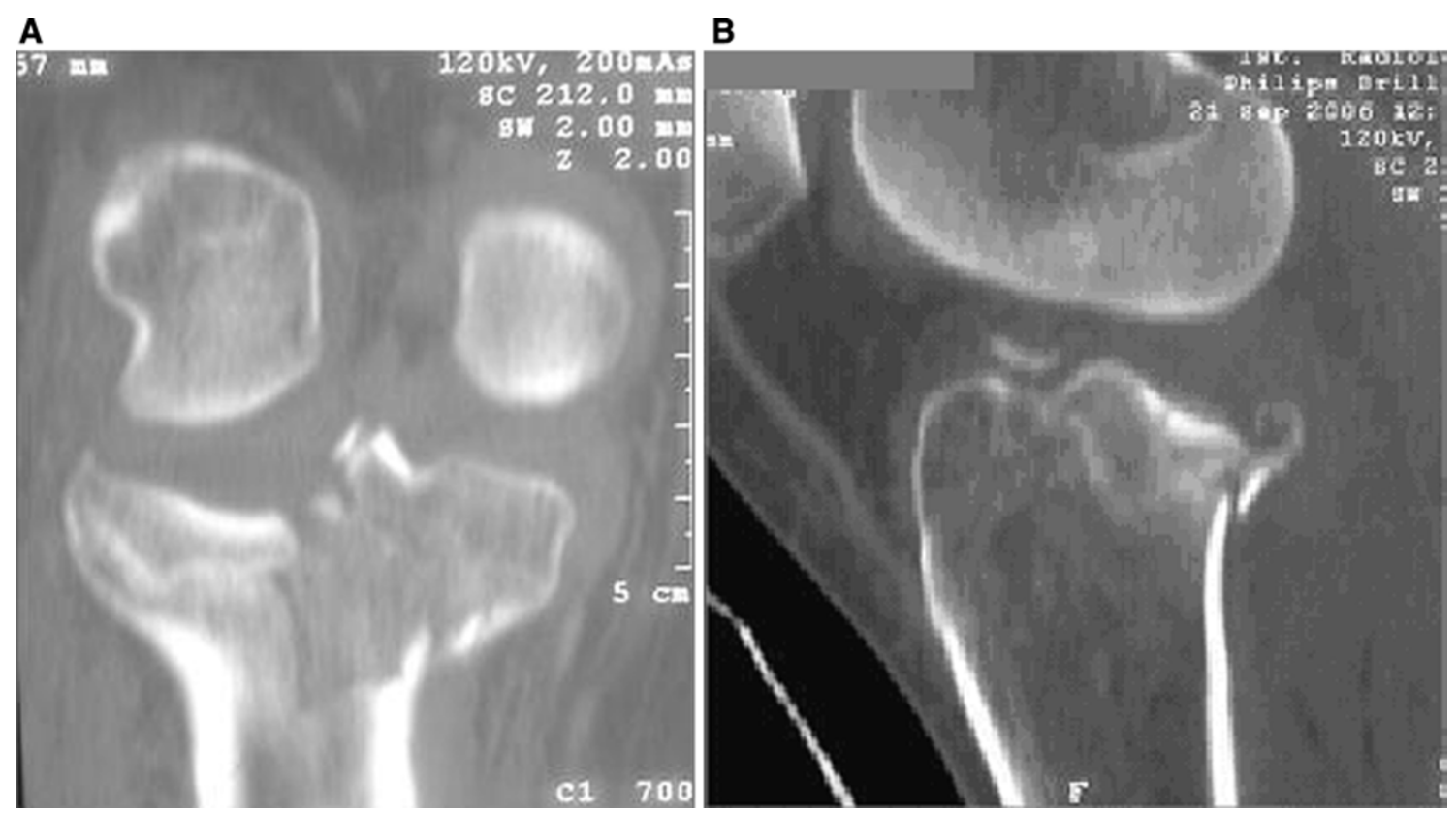

Fig. 9 a Schatzker type V fracture, CT scan. b Schatzker type V fracture, CT scan
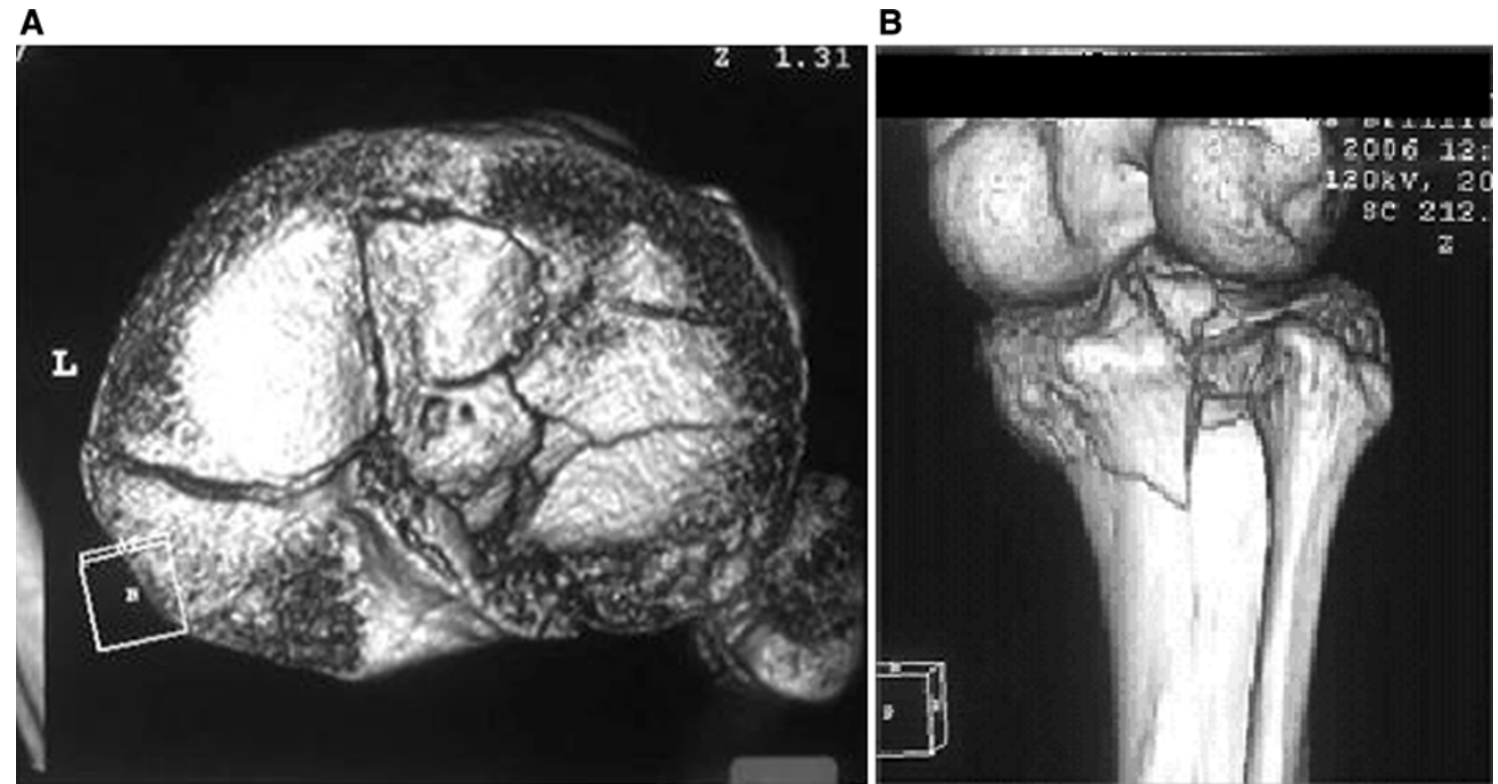

Fig. 10 a Schatzker type V fracture, CT 3D reconstruction. b Schatzker type V fracture, CT 3D reconstruction

Cassard et al. described 26 patients with Schatzker types I-IV fractures treated arthroscopically and concluded that the results were as good as or better than from ORIF [40]. In this series, ARIF treatment of Schatzker V (Figs. 7, 8, $9 \mathrm{a}, \mathrm{b}, 10 \mathrm{a}, \mathrm{b}, 11,12,13,14)$ and VI type fractures (Figs. 15, 16, 17a, b, 18a, b, 19, 20) was carried out in selected cases, typified by a lower degree of comminution, because the water pressure from joint distension could lead to loss of loose cartilage fragments. There was an advantage in performing a single lateral access, arthroscopically inspecting the cartilage, cruciate ligaments and menisci. An image intensifier was used to check the reduction previously obtained using $\mathrm{K}$ wires or cannulated screws. A lateral plate was finally applied with avoidance of arthrotomy and direct open access.

Two cases of deep vein thrombosis were observed in Schatzker VI fractures, 1 in group A and 1 in group B, which resolved after appropriate therapy with low-molecular 


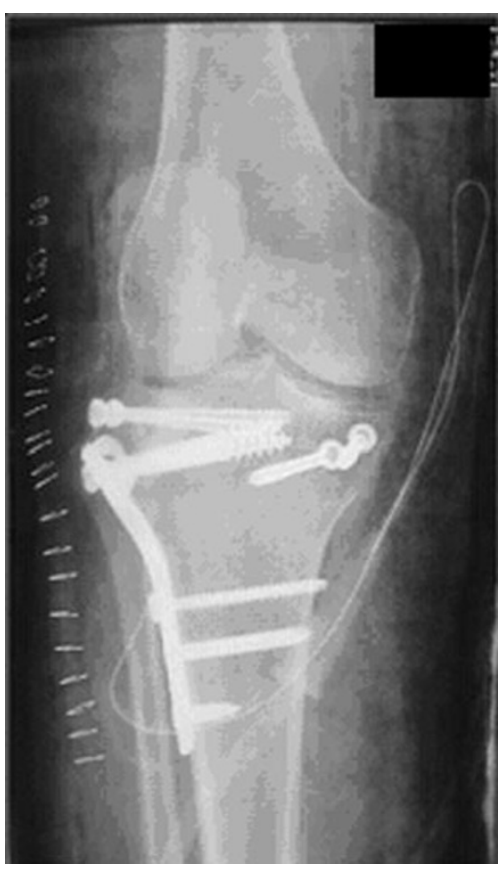

Fig. 11 Schatzker type V fracture, post-op X-rays (AP)

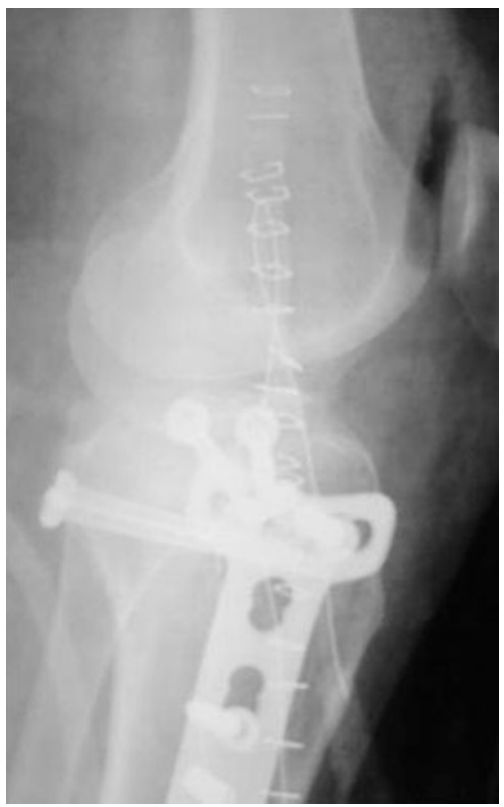

Fig. 12 Schatzker type V fracture, post-op X-rays (LL) infections in patients treated by ARIF technique. Two patients of the ORIF group with Schatzker V type fractures had superficial infections and wound problems which

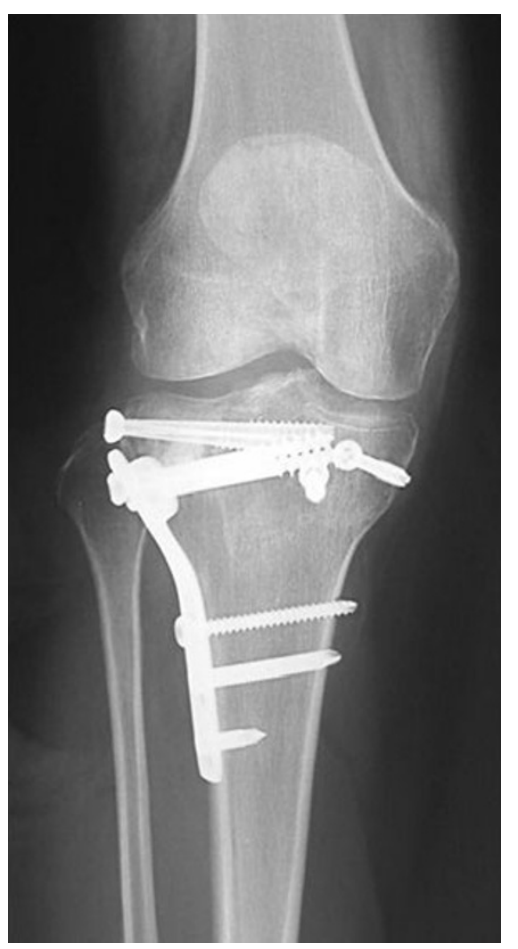

Fig. 13 Schatzker type V fracture, 4 months X-rays (AP)

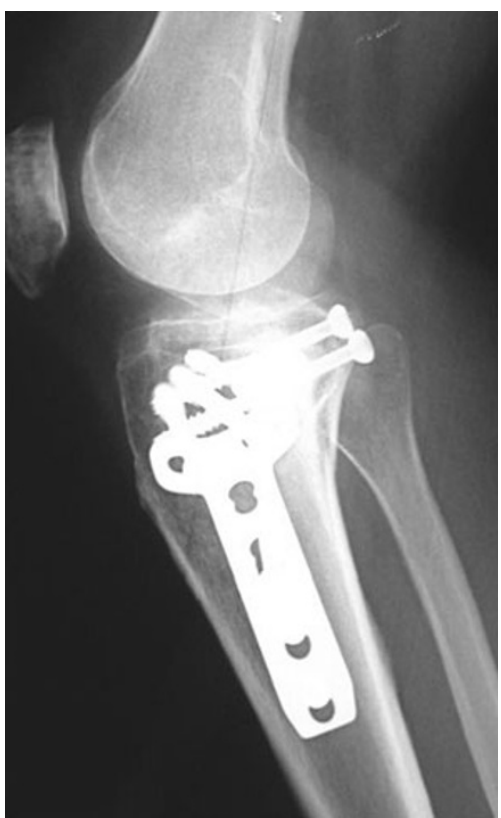

Fig. 14 Schatzker type V fracture, 4 months X-rays (LL)

resolved completely with appropriate antibiotic therapy. There were 2 deep infections also in ORIF group. This complication is well noted by several authors of reports of these complex fractures. Stamer et al. reported a review of 


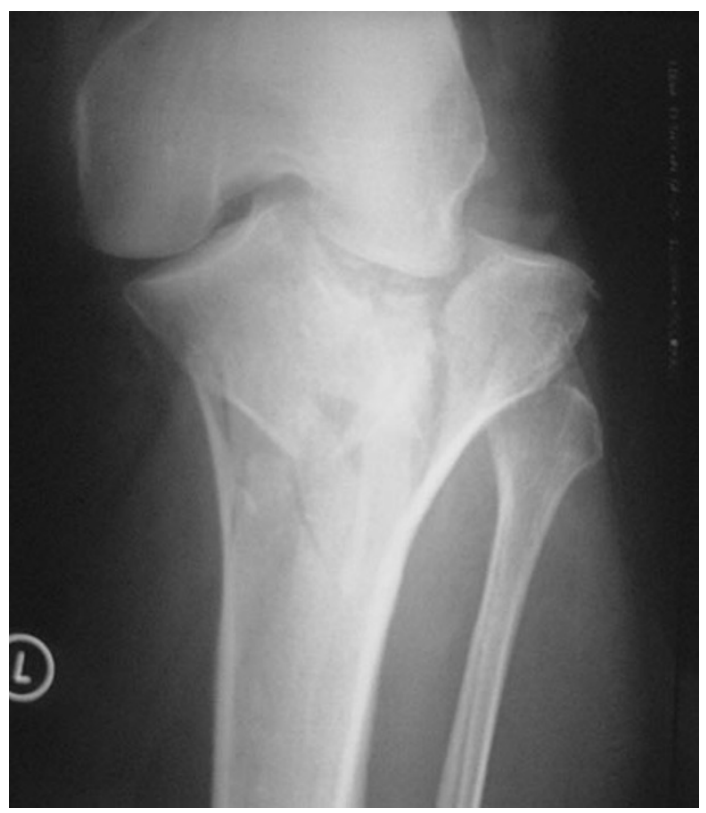

Fig. 15 Schatzker type VI fracture, pre-op X-rays (AP)

23 knees in 22 patients with Schatzker type VI injuries with a $100 \%$ infection rate when extensive dissection was performed to allow the use of a plate in conjunction with external fixation. Six of the 23 knees (26\%) had complications, including 3 deep wound infections, 1 deep vein thrombosis, 1 malunion and 1 pin tract infection [41]. Barei et al. has reported an $8.4 \%$ deep infection rate; the Canadian Orthopaedic Trauma Society reported $17 \%$ [17, 42]. This review has confirmed a major rate of complications seen following open reduction and internal fixation of these difficult fractures, despite the use of ARIF technique. Deep infection in the ORIF group followed $14 \%$ of the types V and VI fractures. However, no infection was observed in the same type of fractures in the ARIF group but it is acknowledged that these were of the lower comminution types.

There were frequent diagnoses of associated lesions: 11 meniscal tears, 3 ACL, 2 MCL and 1 PCL lesions in Schatzker V type of fractures; 7 meniscal tears, 4 ACL, 4 MCL lesions in Schatzker type VI injuries. The meniscal lesions in ARIF group were treated at the same time as the fracture, while the same lesions in ORIF group were treated at a subsequent surgery. For all cases, ruptures of the ACL were treated after fracture healing. The MCL was not repaired in any patient. The single PCL lesion was left untreated because it was not clinically relevant.

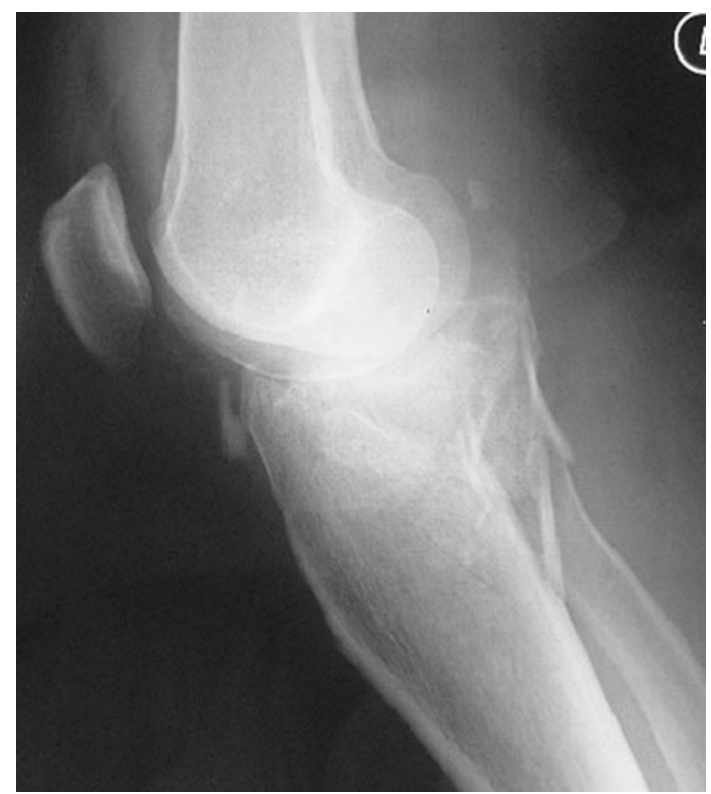

Fig. 16 Schatzker type VI fracture, pre-op X-rays (LL)

The incidence of associated injures with tibial plateau fractures in this series is similar to that reported in the literature [38, 43]. The Canadian Orthopaedic Trauma Society suggested that diagnosis of associated soft-tissue lesions and their subsequent treatment improved clinical outcome [2, 17, 44]. Chan et al. and Hung et al., evaluating soft-tissue lesions, claimed that these are minor injuries but could compromise the final results. They found that their concomitant treatment, during fractures reduction and fixation, may lead to difficulties. This encompassed both meniscal and other soft-tissue lesions including intra-articular ligaments. We hold the view that treatment of meniscal lesions at the same time as fracture reduction could improve the surgical and clinical outcome, whilst ligamentous reconstruction (ACL and PCL) may be technically difficult owing to the fracture comminution and the presence of internal fixation. For these reasons, the surgeon may incorrectly position and fix the new ligament. Another problem would be the contrasting rehabilitation regimes for fracture or ligament reconstruction $[45,46]$.

Post-traumatic arthritis is a common sequela of tibial plateau fractures [38, 47, 48]. Fifteen (68\%) patients with Schatzker V and VI types of fracture were affected by joint degeneration due to malalignment, non-union and severe cartilage damage. Four were treated with knee replacements [49-51]. 
A

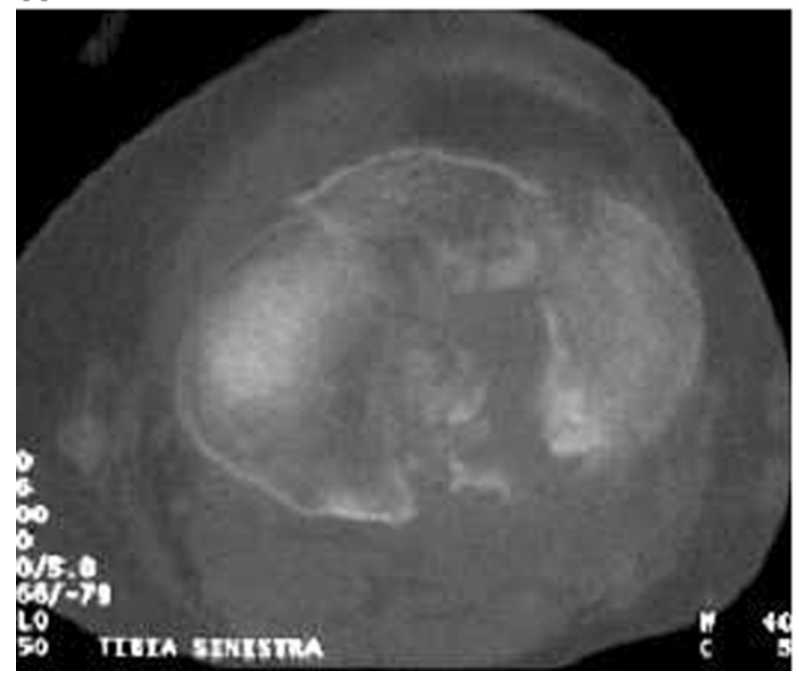

B

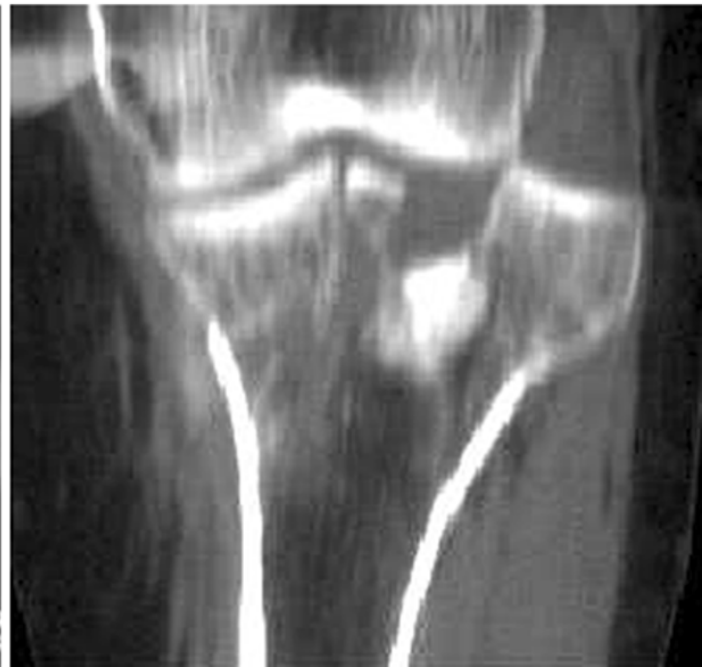

Fig. 17 a Schatzker type VI fracture, CT scan. b Schatzker type VI fracture, CT scan

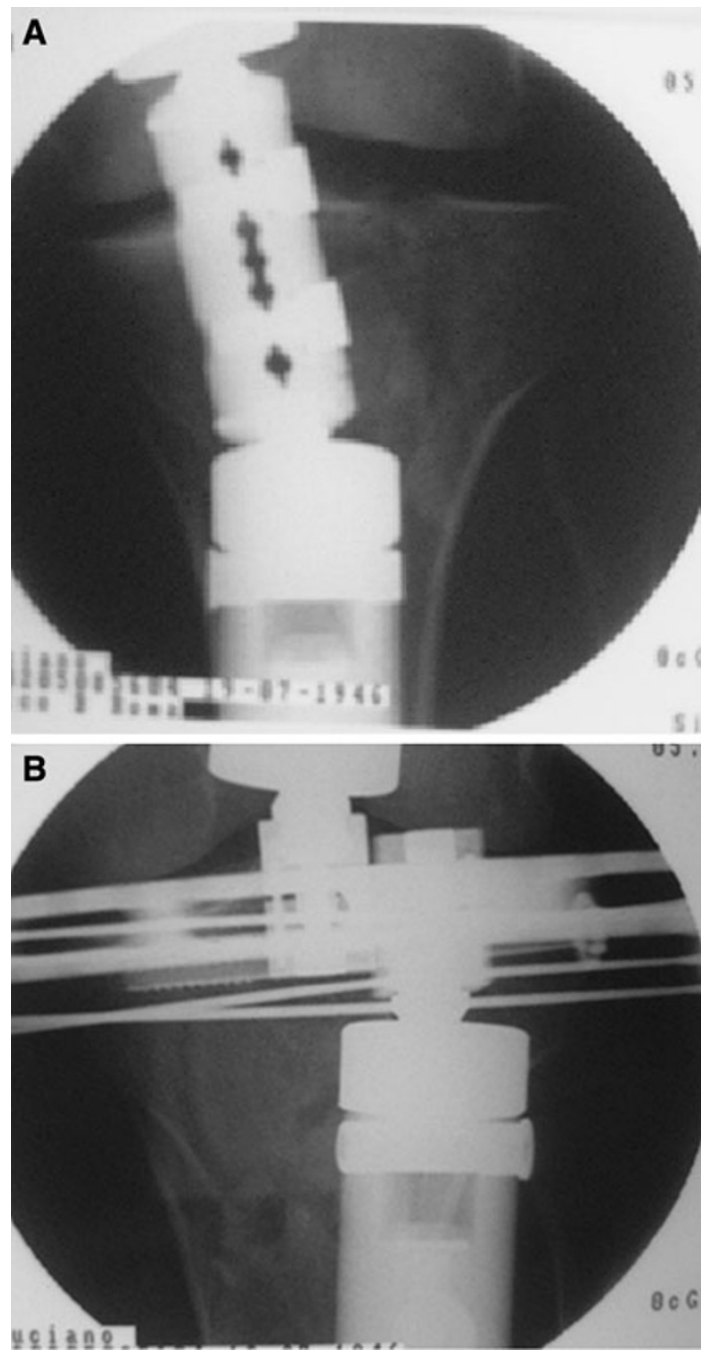

Fig. 18 a Schatzker type VI fracture, temporary spanning fixator. b Schatzker type VI fracture, temporary spanning fixator

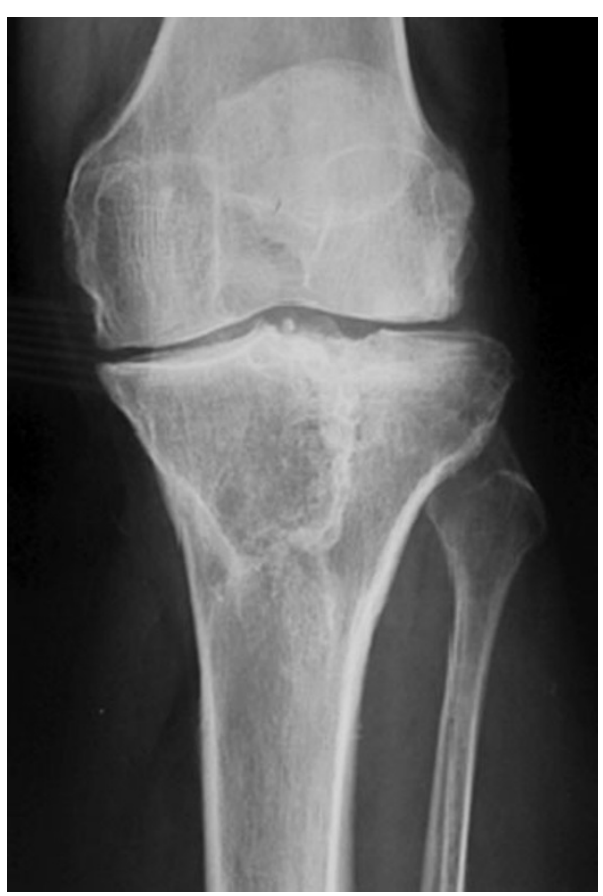

Fig. 19 Schatzker type VI fracture, 1 year after X-rays (AP)

\section{Conclusions}

There were no differences between ARIF and ORIF treatment for type I tibial plateau fractures. We found ARIF treatment preferable when meniscal tears were present as it gave opportunity for simultaneous treatment. In cases of Schatzker II, III and IV fractures, there was a small difference in clinical outcomes in favour of ARIF but not statistically significant. In Schatzker V or VI fractures, ARIF treatment was limited to less comminuted fractures 


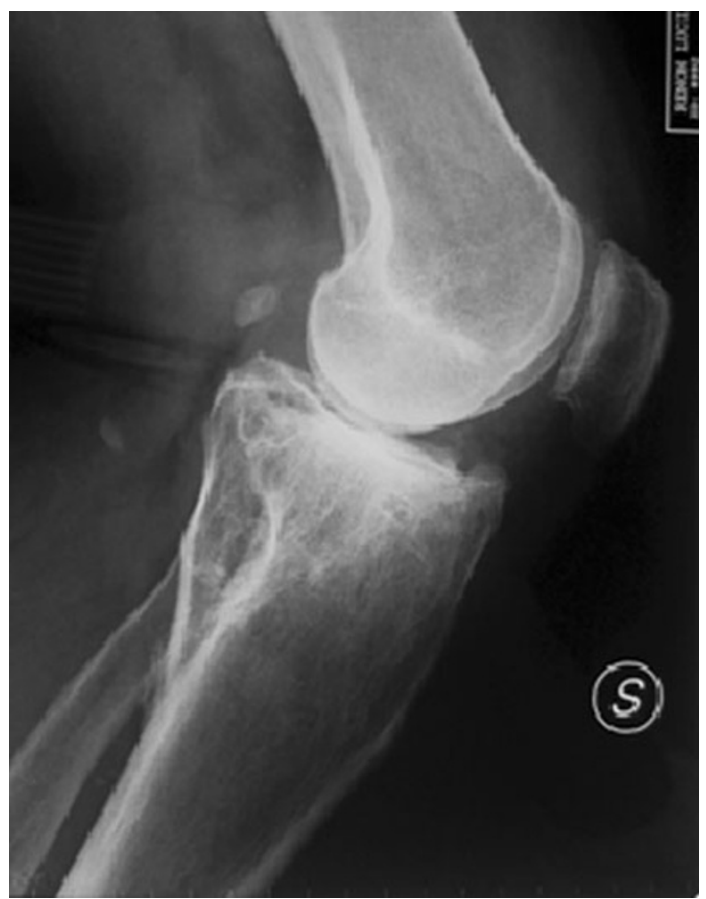

Fig. 20 Schatzker type VI fracture, 1 year after X-rays (LL)

and showed less incidence of infection. Mid-to-long-term clinical results are influenced by the development of posttraumatic arthritis and this itself was related to the severity of the initial cartilage damage, subsequent malalignment and non-union.

Open Access This article is distributed under the terms of the Creative Commons Attribution License which permits any use, distribution, and reproduction in any medium, provided the original author(s) and the source are credited.

\section{References}

1. Belanger M, Fadale P (1997) Compartment syndrome of the leg after arthroscopic examination of a tibial plateau fracture. Case report and review of the literature. Arthroscopy 13:646-651

2. Bennett WF, Browner B (1994) Tibial plateau fractures: a study of associated soft tissue injuries. J Orthop Trauma 8:183-188

3. Crist BD, Della Rocca GJ, Stannard JP (2010) Compartment syndrome surgical management techniques associated with tibial plateau fractures. J Knee Surg 23:3-7

4. Dirschl DR, Dawson PA (2004) Injury severity assessment in tibial plateau fractures. Clin Orthop Relat Res 423:85-92

5. Dirschl DR, Del Gaizo D (2007) Staged management of tibial plateau fractures. Am J Orthop (Belle Mead NJ) 36:12-17

6. Duan XJ, Yang L, Guo L, Chan GX, Dai G (2008) Arthroscopically assisted treatment for Schatzker type I-V tibial plateau fractures. Chin J Traumatol 11(5):288-292

7. Lachiewicz PF, Funcik T (1990) Factors influencing the results of open reduction and internal fixation of tibial plateau fractures. Clin Orthop Relat Res 259:210-215

8. Rommens PM, Coosemans W, Broos PL (1989) The difficult healing of segmental fractures of the tibial shaft. Arch Orthop Trauma Surg 108:238-242
9. Scheerlinck T, Ng CS, Handelberg F, Casteleyn PP (1998) Medium term results of percutaneous, arthroscopically-assisted osteosynthesis of fractures of the tibial plateau. J Bone Joint Surg Br 80:959-964

10. Weinlein J, Schmidt A (2010) Acute compartment syndrome in tibial plateau fracture-beware! J Knee Surg 23:9-16

11. Zhou Z (2009) Arthroscopic percutaneous osteosynthesis of low energy tibial plateau fractures. Zhongguo Xiu Fu Chong Jian Wai Ke Za Zhi 23(11):1316-1318

12. Biggi F, Di Fabio S, D’Antimo C, Trevisani S (2010) Tibial plateau fractures internal fixation with locking plates and the MIPO technique. Injury 41(11):1178-1182

13. Farouk O, Krettek C, Miclau T et al (1997) Minimally invasive plate osteosynthesis and vascularity: preliminary results of a cadaver injection study. Injury 28(1):A7-A12

14. Musahl V, Tarkin I, Kobbe P et al (2009) New trends and techniques in open reduction and internal fixation of fractures of the tibial plateau. J Bone Joint Surg Br 91:426-433

15. Ali AM, Saleh M, Bolongaro S, Yang L (2003) The strength of different fixation techniques for bicondylar tibial plateau fractures-a biomechanical study. Clin Biomech 18:864-870

16. Ali AM, Saleh M, Eastell R, Wigderowitz CA, Rigby AS, Yang L (2006) Influence of bone quality on the strength of internal and external fixation of tibial plateau fractures. J Orthop Res 24:2080-2086

17. Canadian Orthopaedic Trauma Society (2006) Open reduction and internal fixation compared with circular fixator application for bicondylar tibial plateau fractures. Results of a multicenter, prospective, randomized clinical trial. J Bone Joint Surg Am 88:2613-2623

18. Davies R, Holt N, Nayagam S (2005) The care of pin sites with external fixation. J Bone Joint Surg [Br] 87-B:716-719

19. Giotakis N, Panchani SK, Narayan B, Larkin JJ, Al Maskari S, Nayagam S (2010) Segmental fractures of the tibia treated by circular external fixation. J Bone Joint Surg 92-B:687-692

20. Mallik AR, Covall DJ, Whitelaw GP (1992) Internal versus external fixation of bicondylar tibial plateau fractures. Orthop Rev 21:1433-1436

21. Marsh JL, Smith ST, Do TT (1995) External fixation and limited internal fixation for complex fractures of the tibial plateau. J Bone Joint Surg Am 77:661-673

22. Rademakers MV, Kerkhoffs GM, Sierevelt IN et al (2007) Operative treatment of 109 tibial plateau fractures: five- to 27-year follow-up results. J Orthop Trauma 21:5-10

23. Young MJ, Barrack RL (1994) Complications of internal fixation of tibial plateau fractures. Orthop Rev 23:149-154

24. Mui LW, Engelsohn E, Umans H (2007) Comparison of CT and MRI in patients with tibial plateau fracture: can CT findings predict ligament tear or meniscal injury. Skeletal Radiol 36:145-151

25. Te Stroet MA, Holla M, Biert J, Van Kampen A (2011) The value of a CT scan compared to plain radiographs for the classification and treatment plan in tibial plateau fractures. Emerg Radiol 18(4):279-283

26. Buchko GM, Johnson DH (1996) Arthroscopically assisted operative management of tibial plateau fractures. Clin Orthop Rel Res 332:29-36

27. Gill TJ, Moezzi DM, Oates KM, Sterett WI (2001) Arthroscopic reduction and internal fixation of tibial plateau fractures in skiing. Clin Orthop Rel Res 383:243-249

28. Siegler J, Galissier B, Marcheix PS, Charissoux JL, Mabit C, Arnaud JP (2011) Percutaneous fixation of tibial plateau fractures under arthoscopy: a medium term perspective. Orthop Traumatol Surg Res 97:44-50

29. Hsu CJ, Chang WN, Wong CY (2001) Surgical treatment of tibial plateau fracture in elderly patients. Arch Orthop Trauma Surg 121:67-70 
30. Lubokitz JH, Elson WS, Guttmann D (2004) Part I: arthroscopic management of tibial plateau fractures. Arthroscopy 20(12):1063-1070

31. O'Dwyer KJ, Bobic VR (1992) Arthroscopic management of tibial plateau fractures. Injury 23:261-264

32. Schatzker J, McBroom R, Bruce D (1979) The tibial plateau fracture. The Toronto experience 1968-1975. Clin Orthop Relat Res 138:94-104

33. Oestern HJ, Tscherne H (1984) Pathophysiology and classification of soft tissue injuries associated with fractures. In: Tscherne H, Gotzen L (eds) Fractures with soft tissue injuries. Springer, Berlin

34. Egol KA, Tejwani NC, Capla EL, Wolinsky PL, Koval KJ (2005) Staged management of high-energy proximal tibial fractures (OTA types 41): the results of a prospective, standardized protocol. J Orthop Trauma 19:448-455

35. Tscherne H, Lobenhoffer P (1993) Tibial plateau fractures: management and expected results. Clin Orthop Relat Res 292:87-100

36. Insall JN, Ranawat CS, Aglietti P, Shine J (1976) A comparison of four models of total knee replacement prostheses. J Bone Joint Surg [Am] 58-A:754-765

37. Rasmussen PS (1973) Tibial condylar fractures. Impairment of knee joint function as an indication for surgical treatment. J Bone Joint Surg Am 55:1331-1350

38. Chan Y-S, Chiu C-H, Lo Y-P, Chen AC-Y, Hsu K-Y, Wang C-J, Chen W-J (2008) Arthroscopy-assisted surgery for tibial plateau fractures: 2- to 10-year follow-up results. Arthroscopy 24:760-768

39. Chan Y-S, Yuan L-J, Hung S-S, Wang C-J, Shang-Won Y, Chen C-Y, Chao E-K, Lee M (2003) Arthroscopic-assisted reduction with bilateral buttress plate fixation of complex tibial plateau fractures. Arthroscopy 19:974-984

40. Cassard X, Beaufils P, Blin JL, Hardy P (1999) Osteosynthesis under arthroscopic control of separated tibial plateau fractures. 26 case reports. Rev Chir Orthop 85:257-266
41. Stamer DT, Schenk R, Staggers B, Aurori K, Aurori B, Behrens FF (1994) Bicondylar tibial plateau fractures treated with a hybrid ring external fixator: a preliminary study. J Orthop Trauma 8:455-461

42. Barei DP, Nork SE, Mills WJ, Henley MB, Benirschke SK (2004) Complications associated with internal fixation of high-energy bicondylar tibial plateau fractures utilizing a two-incision technique. J Orthop Trauma 18:649-657

43. Mohamed Zaki A-H, Chung-Hsun C, Yi-Sheng C, Yang-Pin L, Jau-Wen H, Kuo-Yao H, Ching-Jen W (2006) Arthroscopic evaluation of soft tissue injuries in tibial plateau fractures: retrospective analysis of 98 cases. Arthroscopy 22:669-675

44. Holt MD, Williams LA, Dent CM (1995) MRI in the management of tibial plateau fractures. Injury 26:595-599

45. Chan YS, Yuan LJ, Hung SS et al (2003) Arthroscopicallyassisted reduction with bilateral buttress plate fixation of complex tibial plateau fractures. Arthroscopy 19:974-984

46. Hung SS, Chao EK, Chan YS et al (2003) Arthroscopicallyassisted osteosynthesis for tibial plateau fractures. J Trauma 54:356-363

47. Giannoudis PV, Tzioupis C, Papathanassopoulos A, Obakponovwe O, Roberts C (2010) Articular step-off and risk of post-traumatic osteoarthritis. Evidence today. Injury Int J Care Injured 41:986-995

48. Marsh JL, Buckwalter J, Gelberman R et al (2002) Articular fractures: does an anatomic reduction really change the result? J Bone Joint Surg Am 84-A:1259-1271

49. Honkonen SE (1995) Degenerative arthritis after tibial plateau fractures. J Orthop Trauma 9:273-277

50. Moore TM, Patzakis MJ, Harvey JP (1987) Tibial plateau fractures: definition, demographics, treatment rationale, and longterm results of closed traction management or operative reduction. J Orthop Trauma 1:97-119

51. Woll TS, Duwelius PJ (1992) The segmental tibial fracture. Clin Orthop 281:204-207 